\title{
The Influence of Extrusion Ratio on Contact Stresses and Die Elastic Deformations in the Case of Cold Backward Extrusion
}

\author{
Tomaž Pepelnjak ${ }^{1, *}$ - Mladomir Milutinović2 - Miroslav Plančak ${ }^{2}$ - Dragiša Vilotić2 ${ }^{-}$ \\ Saša Randjelovićc 3 - Dejan Movrin ${ }^{2}$ \\ ${ }^{1}$ University of Ljubljana, Faculty of Mechanical Engineering, Slovenia \\ 2 University of Novi Sad, Faculty of Technical Sciences, Serbia \\ ${ }^{3}$ University of Niš, Mechanical Engineering Faculty, Serbia
}

In this paper, the distribution of contact stresses along the die-workpiece interface as well as elastic deformation behavior of the die in the cold backward extrusion of steel billets have been investigated both experimentally and numerically. For the experiments, a special tooling set including a pin load cell measuring device was designed and made. Contact stresses were recorded at various points in time and at various locations during the extrusion process, i.e. for different punch strokes (part's bottom thickness). The research focus was on determining the extrusion ratio's influence on the distribution of the contact stresses and therefore the experiments were performed using five punches of different head diameters. In the next step, based on the measured contact stresses, radial displacements of the inner die wall were calculated by applying Lame's equation. Furthermore, an extended finite element analysis of the investigated extrusion process was carried out using Simufact.forming software. The results of numerical simulations for the contact stresses were compared with experiments. The benefits and weaknesses of the pin load cell measuring technique and Lame's formula when it is employed for determination of the die elastic deformation were also examined, as well as were the contribution of the die elastic deformation to dimensional errors of the extruded parts.

Keywords: backward extrusion, contact stresses, die elastic deformation, pin load cell, finite element method

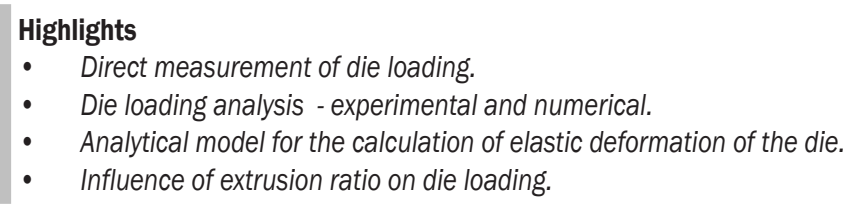

\section{O INTRODUCTION}

Cold extrusion is a forming technology that enables mass production of parts in a wide range of shapes and dimensions with increased mechanical properties and narrow tolerances, at lower costs. This is why the main consumers of cold extruded parts are the automotive, railway, aircraft, and military industries, in which cold extruded components are integral components of assemblies where dynamic load, and high levels of reliability and human safety are critical considerations [1] and [2].

In cold extrusion processes, the tool set is exposed to high contact stresses, which, in certain cases, may be limiting factors in applying this technology [3]. This is especially true for extruded steel samples. A high level of internal pressure and especially local stress concentration directly affect die wear occurrence, tooling damage and failure [4] as well changes in die geometry [5] which altogether result in poor part accuracy [6] and tool life [7]. The tooling concept, design, and manufacturing procedure also depend on the amount of acting stresses [8]. Therefore, in order to reduce problems and to design a tool set suitable for cold extrusion, tool loading should be thoroughly researched, particularly radial stresses at the die wallworkpiece interface [9]. A better understanding of the stress state in the die means greater possibilities for optimizing its design.

The stress state in the tooling elements during cold extrusion depends primarily on the die and punch geometry, material properties of the workpiece, and process conditions [2]. The stress state can be determined using several approaches. Basic information about tool set loading (stress distribution along the workpiece boundaries) may be obtained by theoretical methods (slab method, slip line, upper bound, etc.) [10]. This is the fastest and simplest way, but it is limited to a few cases of simple workpiece geometry. Furthermore, most of the theoretical solutions for contact stresses in extrusion are derived based on a number of assumptions and simplifications, which, in turn, may lead to a significant deviation from the real values.

A significant improvement in die stress analysis and design procedure has been achieved by introducing and developing numerical methods and computer-aided engineering (CAE) software. Simulation based on the finite element method (FEM) has made it possible to calculate the stress distribution 
at different cross sections of the die with the features of their shape and thermo-mechanical conditions taken into account [11] and [12], as well as to predict die damages and estimate tool life [13], to analyze die elastic deformation and the effects on part dimensional accuracy [14], and to optimize die geometry and pre-stressing procedures [15]. In some cases, FEM analysis is combined with certain methods of physical modeling [16] and artificial intelligence [17]. The goal is to gain more reliable data about loading, pressures and boundary conditions, which are then used as an input data for the simulation.

Experimental results for contact stresses are essential to verify the analytical and numerical calculations. For this reason, a lot of efforts have been invested in the development of experimental techniques and devices for determining contact stresses ranging from simple sensors and tooling with holes up to membrane system, profile foil method, pin load cell method, and strain gauges [18] and [19].

The main objective of this paper is to experimentally determine the intensity and distribution of the contact (radial) stress on the inner die wall in the case of backward cup extrusion of steel specimens for a wide range of the extrusion ratios and at the various points in the process development (various bottom thicknesses of the can). For that purpose a measuring device based on the pin load cell technique and special tooling with a set of inserts of different thicknesses have been designed and made. The pin load cell technique is one of the most reliable experimental methods for measuring contact stresses in metal forming operations since the measuring device is in direct contact with the extruded material [19]. This yields a dynamic output, which simulates the non-steady process conditions that are typical in these processes and enables the measurement of both normal and tangential stresses. This technique characterizes a relatively simple measuring procedure since minimal modifications in the design of the tool set are needed. Basic details of the pin load techniques and some technical problems associate with its use are elaborated in this paper. Furthermore, an extensive analysis of the stress-strain state of the extrusion die including the process simulation was performed employing Simufact.forming software based on FEM. Finally, based on the measured contact stresses, the die elastic deformations in the radial direction were calculated by using Lame's equation and compared with FEM results in order to evaluate the accuracy of this approach. Relevant data related to the stressstain state of the extrusion die are essential to properly design both the die and process parameters. Therefore, the findings could also be valuable to engineers in the forming industry in addition to the academic community.

\section{THE PIN LOAD CELL MEASURING TECHNIQUE}

The principal scheme of the pin load cell technique and a photo of the device assembly are given in Figs. 1 and 2 , respectively.

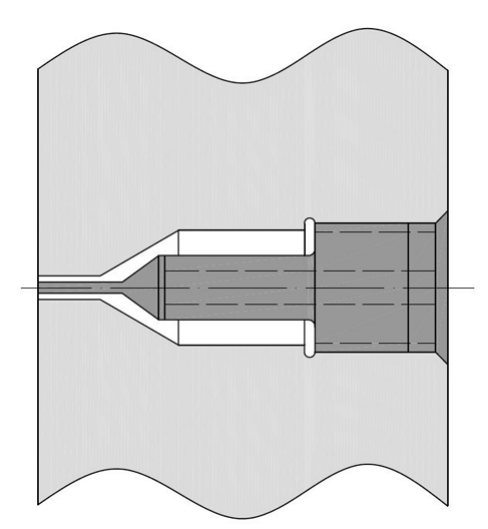

Fig. 1. Pin load cell built into the die wall

The pin load cell (Fig. 2) device consists of a small cylindrical pin (1), strain gauge (2), and threads (3). The cylindrical pin passes through the designated hole in the die body and its head/tip (top surface) is aligned with the inner surface of the die wall thus enabling full contact with the workpiece material. During the forming process, the workpiece material pushes (presses) the pin head causing elastic compression of the pin and remaining part of the cell. This compression is measured by strain gauges (2) attached to the lower part of the cell.

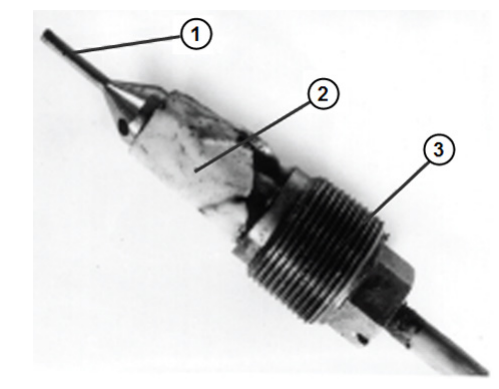

Fig. 2. Pin load cell device with main components: (1) pin, (2) strain gauge, (3) thread

The effectiveness of this technique and the accuracy of the measured contact stress depends on several factors, one of which is the friction occuring between the pin and die hole. It comes from tangential 
stresses acting on the pin head during the forming process. Since the calibration procedure does not take into account friction force (pre-calibration is performed only using normal force), any pressure drop due to friction cannot be detected. In order to reduce this friction and measurement uncertainty, the clearance between the pin and the die hole should be as large as possible. However, this may lead to another problem - the risk of the workpiece material being extruded in the gap between pin and hole. This is an undesirable feature, because it hampers the pin movement inside the hole. So, a compromise has to be made regarding the radial clearance between pin and hole.

The axial pin head position relative to the die surface during the forming process is very sensitive to the rigidity of the pin assembly and the die (Fig. $3)$. The difference in the rigidity may cause more or less deviation of the measured contact stress from the real value. If the pin head and die surface are leveled before deformation ( $\Delta h=0$, Fig. 3), then the following situations are possible during deformation:

a) The rigidity of the pin assembly is greater than the rigidity of the die. Therefore the die deforms elastically more than the pin assembly and the pin protrudes from the die $(+\Delta h)$. This results in a measured value that is higher than the actual one as the pin is not only loaded by the material directly above its head $(\mathrm{N})$, but also by the surrounding material.

b) The rigidity of the pin assembly is less than the rigidity of the die. In this case the pin head is below the die surface $(-\Delta h)$ and indicates lower stress values as it is loaded by only a portion of the material above its head $(\mathrm{N})$, whereas the surrounding area of the die undergoes loading from (M).
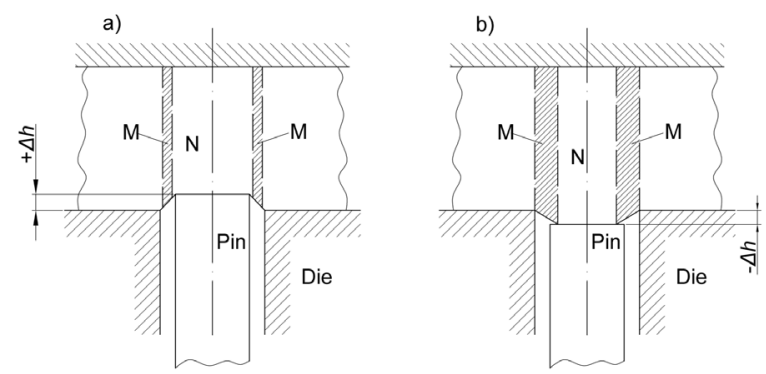

Fig. 3. Relative pin position

c) The rigidity of the pin assembly and the die are equal. The same rigidity yields the same elastic deformations i.e. the pin head and die surface are the same level $(\Delta h=0)$ and the pin produces an output which gives the correct values of the normal contact stress. This is considered to be an ideal case.

\section{EXPERIMENTAL}

Measuring the radial contact stresses using the pin load cell device at different points on the die wall during backward extrusion is possible in two ways:

1. using a tool with two or more pin load cells built into the die wall;

2. using a tool with only one pin load cell and replaceable die bottoms of various thickness.

The main drawback of the first variant with two or more pin loads is weakening of the die. Therefore, in the present investigation, the second option is chosen.

The tooling set used in the experiment is shown in Fig. 4. Five different die bottoms of various thicknesses are used in order to simulate five different contact points between the workpiece and the die. The locations (the axial distance from the bottom of the measuring points $(\mathrm{A}-\mathrm{E})$ are given in Fig. 5. At each point, the measurement was repeated for five different instantaneous positions of the punch i.e. the punch strokes $(s=2 \mathrm{~mm}, 4 \mathrm{~mm}, 10 \mathrm{~mm}, 14 \mathrm{~mm}$ and $18 \mathrm{~mm}$, see Fig. 5). The face shape of the punch was a flat/conical face shape and designed according to the recommendation of the International Cold Forging Group [2].

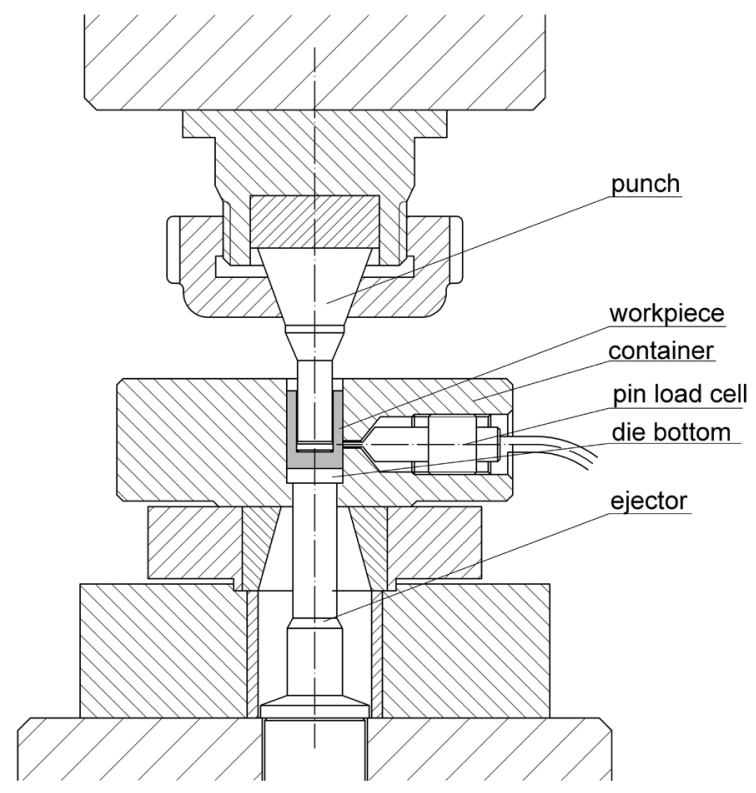

Fig. 4. Scheme of the tooling 


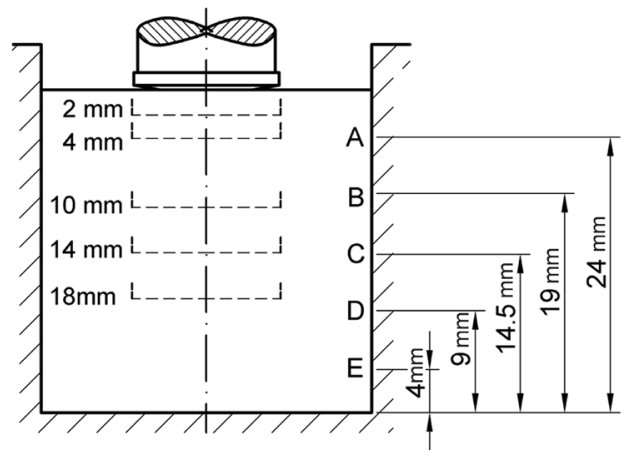

Fig. 5. Locations of measuring points

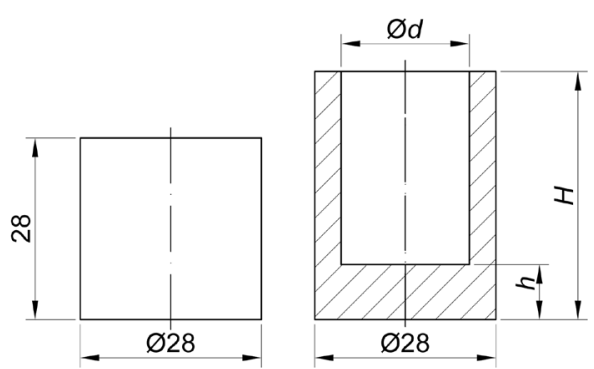

Fig. 6. Billet and workpiece geometry

Cylindrical billets $(\varnothing 28 \mathrm{~mm} \times 28 \mathrm{~mm})$ made from low carbonated steel (1.0401 according to EN 10027-2 [20]) were used in the experiment. All billets were soft annealed and phosphate coated, with molybdenum disulphide $\left(\mathrm{MoS}_{2}\right)$ applied as a lubricant. The geometry of the billet and workpiece is given in Fig. 6. The inner diameter of the workpiece was also varied at five levels according to the Table 1 , in which the corresponding values of the extrusion ratio and true strain are given. The punches and die were made from tool steel 1.2601 according to [20], the hardness after heat treatments were $60 \mathrm{HRC}$ and $58 \mathrm{HRC}$, respectively.

Table 1. Punch geometry and process parameters

\begin{tabular}{lccccc}
\hline $\begin{array}{l}\text { Punch diameter } \\
d[\mathrm{~mm}]\end{array}$ & 12 & 14.25 & 16.85 & 18.80 & 20.33 \\
\hline $\begin{array}{l}\text { Extrusion ratio } \\
e_{p}=A_{0} /\left(A_{0}-A_{1}\right)\end{array}$ & 1.22 & 1.35 & 1.57 & 1.82 & 2.11 \\
\hline $\begin{array}{l}\text { True strain } \\
\varepsilon=\ln \left(A_{0} /\left(A_{0}-A_{1}\right)\right)\end{array}$ & 0.2 & 0.3 & 0.45 & 0.6 & 0.75
\end{tabular}

\section{FEM ANALYSES}

Backward extrusion was also investigated by numerical simulation using a commercial software package and FEM. The applied software enables detailed analysis of forming processes from different aspects including simulation of tool behavior. Recent developments of remeshing methods and advances in computational technology have further upgraded capability and efficiency of this technique and the software, as well as the accuracy of the obtained results [21].

The focus of the FEA is on the die radial stress distribution and load, which effect the elastic deformation of the die during the investigated process. During simulation, an axially-symmetric 2D FEM model of the backward extrusion was used. The modeling procedure started with the creation of a $3 \mathrm{D}$ model of the tooling and workpiece in CAD software SolidEdge which was then imported into the simulation package. Elastic-plastic material behavior for the workpiece was chosen as the punch and the dies were treated as elastic bodies. The flow curve in the analytic form necessary for FEM simulation was obtained by the Rastegaev compression test. A suitable tool steel from the simulation database was selected for the punch and die material. The meshing procedure was initially performed under different mesh criteria as well as different sizes and types of elements with the goal of checking the convergence of the numerical solution. Finally, after a few iterations, the advancing Front Quad mesher and the quad elements with a size of $1 \mathrm{~mm}$ for the workpiece, as well "quadtree mesher" and the quad elements of $2.1 \mathrm{~mm}$ for the die and the punch were chosen. The remeshing of the starting elements was executed in the most highly deformed zones of the workpiece at every five increments in order to minimize the effect of tool penetration through the elements due to large workpiece deformations. Coupled thermo-mechanical FEM analysis is performed under low friction conditions $(\mu=0.09)$.

\section{RESULTS}

\subsection{Radial Stresses at the Container Wall}

Radial stress distributions at the container wall for five different instantaneous punch positions ( $2 \mathrm{~mm}, 4$ $\mathrm{mm}, 10 \mathrm{~mm}, 14 \mathrm{~mm}$, and $18 \mathrm{~mm}$ ) and five different punch diameters $(12 \mathrm{~mm}, 14.25 \mathrm{~mm}, 16.85 \mathrm{~mm}$, $18.80 \mathrm{~mm}$, and $20.33 \mathrm{~mm}$ ), obtained by FE analysis and experimentally, are shown in Figs. 7 to 11. The experimental distribution curves were obtained based on measurements taken at 5 points on the wall, according to Fig. 5.

As an example (Fig. 7), if the punch with a diameter of $12 \mathrm{~mm}\left(e_{p}=1.22, \varepsilon=0.2\right)$ travels for 4 $\mathrm{mm}$, the value of the radial stress at point " $\mathrm{D}$ " of the 


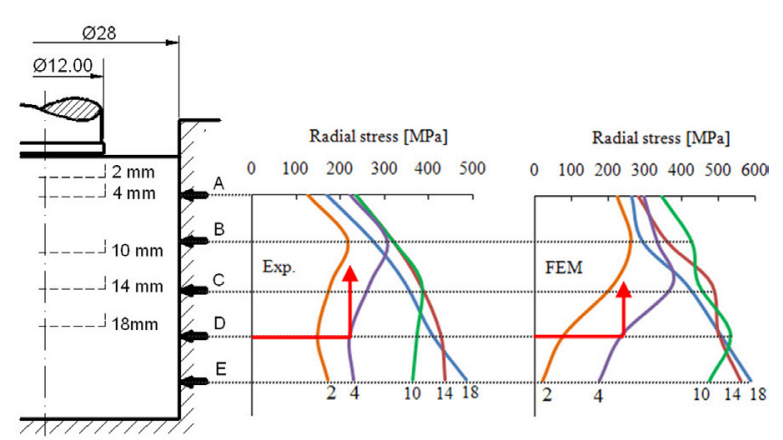

Fig. 7. Distribution of radial stresses at inner die wall vectors for $e_{p}=1.22(\varepsilon=0.2)$

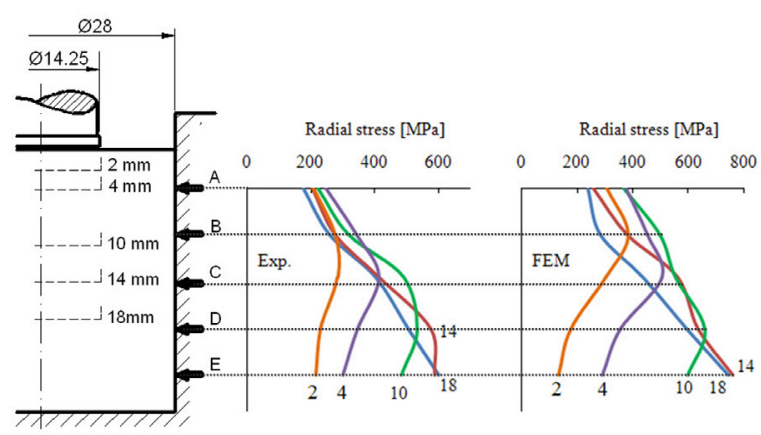

Fig. 8. Distribution of radial stress at inner die wall for $e_{p}=1.35(\varepsilon=0.3)$

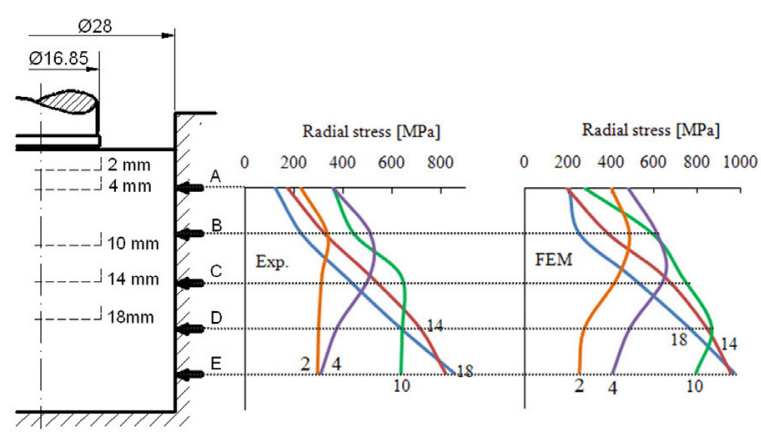

Fig. 9. Distribution of radial stress at inner die wall for $e_{p}=1.57(\varepsilon=0.45)$

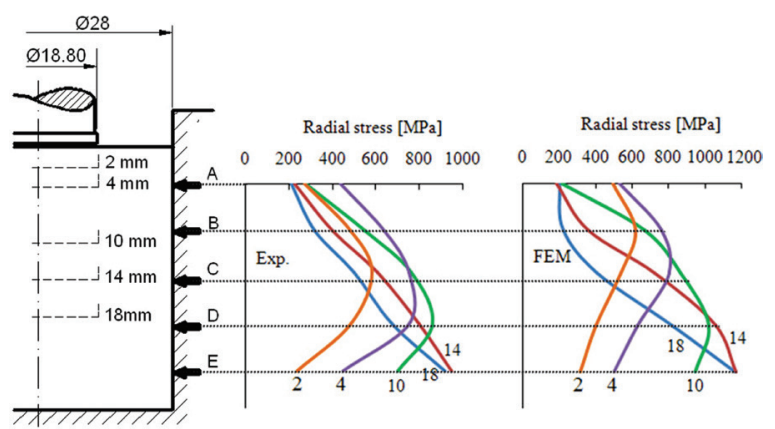

Fig. 10. Distribution of radial stress at inner die wall for $e_{p}=1.82(\varepsilon=0.6)$

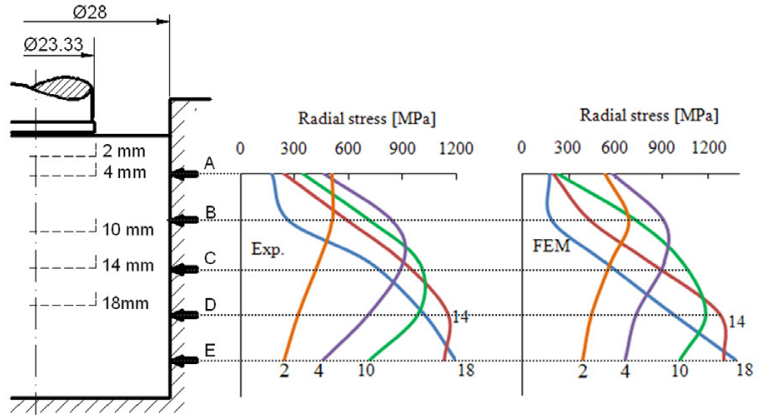

Fig. 11. Distribution of radial stress at inner die wall for $e_{p}=2.11(\varepsilon=0.75)$

container wall is $220 \mathrm{MPa}$ (experimental), i.e. 240 $\mathrm{MPa}$ (FEM).

Generally, it could be concluded that every point on the container wall is subjected to radial stress whose value is changeable and depends on the instantaneous position of the punch head. The maximal amount of $\sigma_{r}$ at a given point appears at the moment when the punch head is at a certain distance from this position and corresponds to the point of maximal contact pressure. Basically, a higher $\sigma_{r}$ corresponds to a higher extrusion ratio $e_{p}$. The highest $\sigma_{r}$ values always occur at the end of the backward extrusion process, i.e. when the punch has reached its final position (in the current study this is the $18 \mathrm{~mm}$ punch stroke). Fig. 12 shows the relationship between the maximal radial stress at the container wall $\sigma_{r, \max }$ and the extrusion ratio $e_{p}$ obtained by FE and experimentally. It can be seen that this stress increases from the initial value of $484 \mathrm{MPa}$ (Exp.) i.e. $588 \mathrm{MPa}$ (FEM) to the absolute maximal amount of $1195 \mathrm{MPa}$ (Exp.) and $1372 \mathrm{MPa}$ (FEM), respectively.

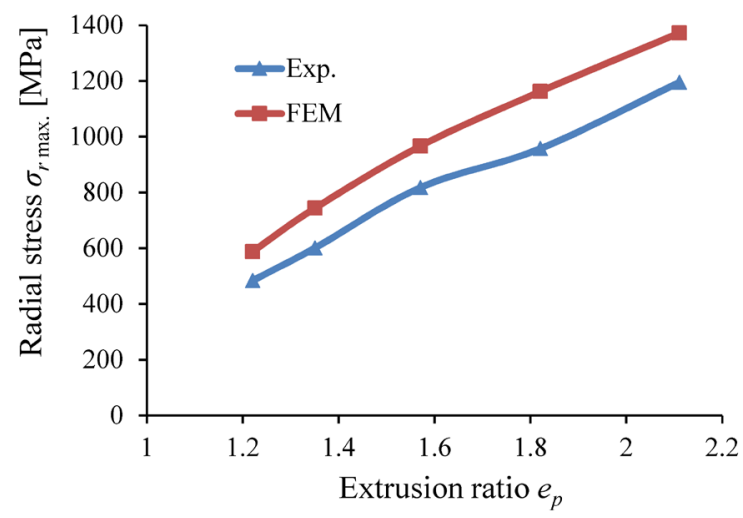

Fig. 12. Maximal radial stresses against extrusion ratio

A comparison between FE and the experimental results shows that the $\mathrm{FE}$ analysis gives somewhat 
higher $\sigma_{r}$ values ( $15 \%$ to $20 \%$ ) than the experimental measurements. This discrepancy can be attributed to inaccurate calibration of the pin load cell, friction between the pin and pin hole, as well as to the improper modeling of materials and boundary conditions in FEA.

\subsection{Die Elastic Deformation}

Contact pressure acting on the die wall results in its elastic deformation. Positive elastic radial displacement of the internal die wall introduces positive dimensional errors to both the inner and outer diameter of the extruded cup [6]. In addition, since the contact pressure is variable along the axial direction, the radial displacement of the internal die wall also vary, i.e. the die wall profile will differ from the nominal one. Therefore, an exact prediction of die elastic behavior during forming process is a key factor for improving the accuracy of cold formed components [22].

If radial contact stresses on the inner die wall are known, then die radial displacement $(\Delta r)$ can be evaluated using Lame's formula, Eq. (1) [14]. The formula was originally derived for determination of the stress-strain state in the case of a thick cylinder subjected to internal pressure only, but it is often used to solve different engineering problems in the area of elastic mechanics [18]. In this paper, the profile of the inner die wall was determined by substituting the measured contact stresses into Lame's formula.

Thus the elastic radial displacement is:

$$
\Delta r=r \cdot e_{\theta}=\frac{p_{i} \cdot r^{2}}{E\left(R^{2}-r^{2}\right)}\left[(1-v)+(1+v) \frac{R^{2}}{r^{2}}\right] r,
$$

where $p_{i}$ is internal pressure (at inner surface $p_{i}=-\sigma_{r}$ ), $e_{\theta}$ circumferential strain, $r$ inner diameter of the die, $R$ outer diameter of the die, $E$ Young's modulus of the die material $(E=210 \mathrm{GPa})$ and $v$ Poisson's ratio $(v=$ 0.29).

The layout of the die wall radial elastic displacements for different punch positions (punch stroke $s$ ) in the case of the extrusion ratio $e_{p}=2.11$ $(\varepsilon=0.75)$ obtained by FEM simulation is depicted in Fig. 13. Pictures show that the change in the die geometry is most evident on the part of the inner die wall (and zone around) where maximal radial stresses act. This region moves down, expanding radially with the punch stroke (see also Fig. 11). In contrast, the rest of the die volume remains almost undeformed during
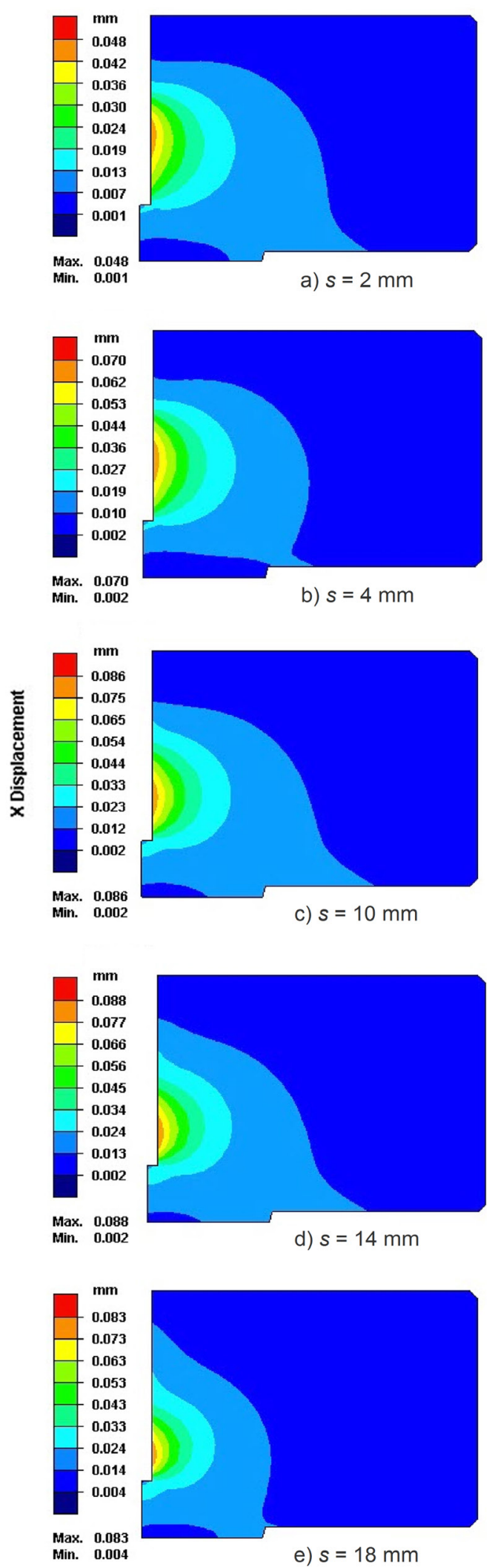

Fig. 13. Radial elastic deviations of the die predicted by FEM (extrusion ration $e_{p}=2.11$ ) 

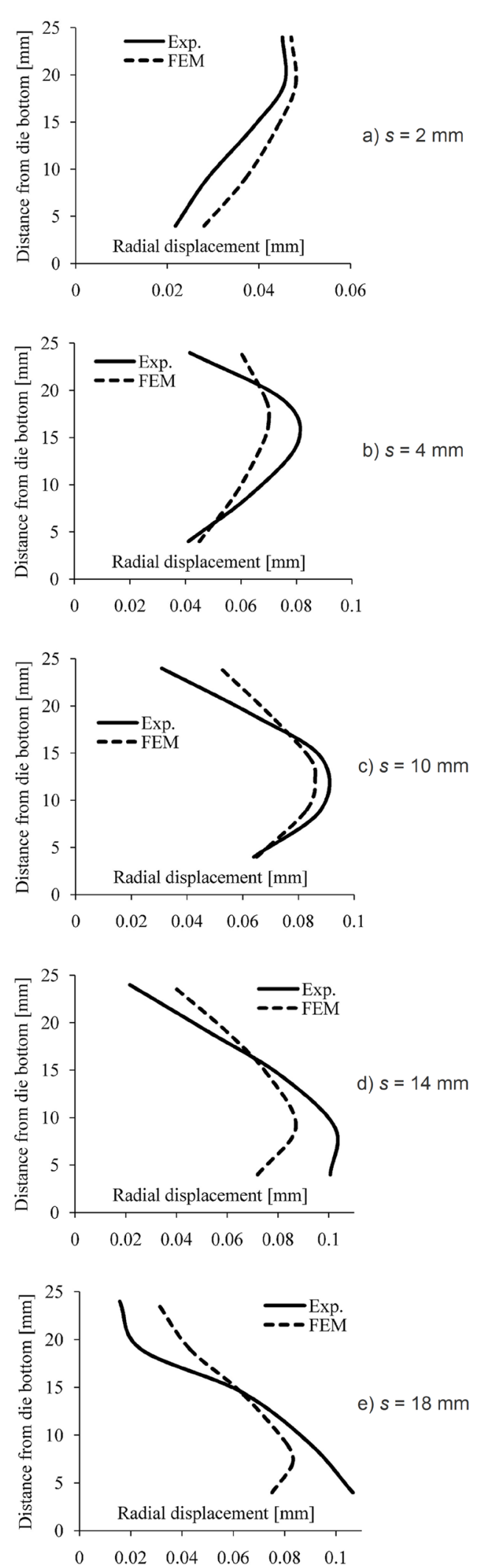

Fig. 14. FEM and analytical results for the radial displacement of the inner die wall $\left(e_{p}=2.11\right)$ the entire extrusion process. As expected, the minimal die displacement occurs at the outer die wall.

A comparison of $\Delta r$ values predicted by FEM and obtained analytically by Eq. (1), for $e_{p}=2.11$, is given in Fig. 14. In Eq. (1), the experimental values of radial stress $p_{i}$ are substituted. As it can be seen, the analytically calculated die profile is directly proportional to the experimentally obtained pressure distribution, as the rest of the Eq. (1) is constant. The maximum radial displacement $(\Delta r=0.1065 \mathrm{~mm})$ is related to the maximum punch stroke $(s=18 \mathrm{~mm})$ and to the point of maximal measured radial stress. On the other hand, the profile predicted by FEM indicates that there is some discrepancy in the distribution of radial strain and radial stress. These differences arise with the punch stroke. Maximal displacement of the internal die wall $(\Delta r=0.088 \mathrm{~mm})$ is not found at the maximal punch stoke $(s=18 \mathrm{~mm})$ and the point of the maximal predicted radial stress (Fig. 11), but rather at the punch stroke $s=14 \mathrm{~mm}$. The reason for this is the die geometry, i.e. an increase in die stiffness in the area near the die bottom due to reduction of the die inner diameter. For a punch stroke of $18 \mathrm{~mm}$ the point of maximum radial stress is closer to the die bottom compared to the punch stroke of $14 \mathrm{~mm}$ and thus the maximal radial deformation is smaller.

The change in die stiffness along the axial axis could not be taken into account in Eq. (1), which has a negative effect on the accuracy of the solution. Furthermore, Lame's formula is developed with the assumption that any section of the cylinder will remain plane before and after the application of pressure, i.e. that strain along the axial axis is constant. Since this precondition is not met here it can be considered as an additional source of inaccuracy in the analytical solution.

Another drawback of the analytical solution is related to the impossibility of considering die surface hardness, which influences the die elastic behavior significantly. The results are generally higher values of the maximal radial displacement (except for $s=2$ $\mathrm{mm}$ ) compared to the FEM ones (Fig. 14) even though experimentally recorded values of the contact stresses are lower than FEM predicted (Fig. 11). This can be attributed to strong intermolecular bonds, which occur in the case of hardened material due to which both local elasto-plastic and overall elastic deformation are considerably reduced, as well as the influence of local peaks of contact stresses to the surface curvature. A much better illustration of the hardening effect on material elastic behavior is given in Fig. 15, where the radial displacements of the die made from hardened (Fig. 15b real case) and non-hardened (Fig. 
15a demo case) material (predicted by FEM, punch stroke $18 \mathrm{~mm}$ ) are shown. Comparing both results, the difference in the maximum values is more than obvious.
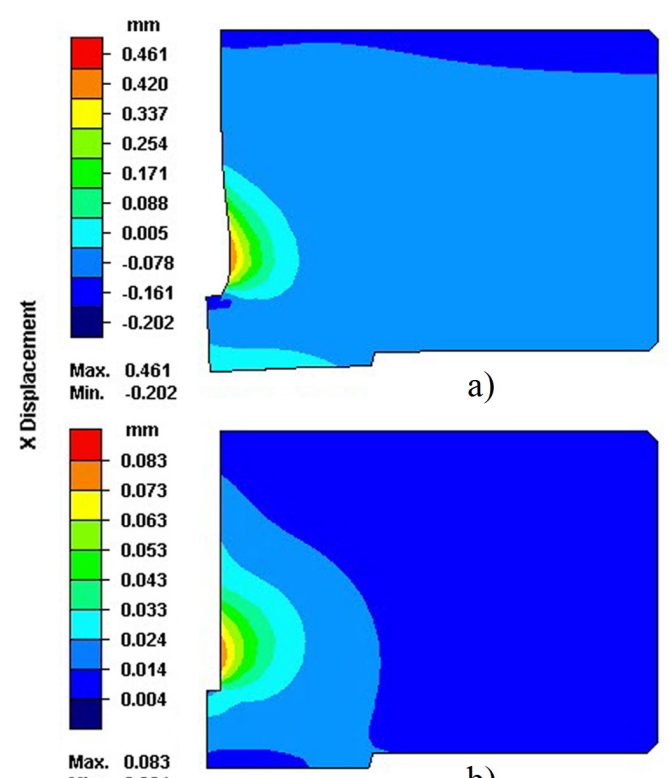

a)

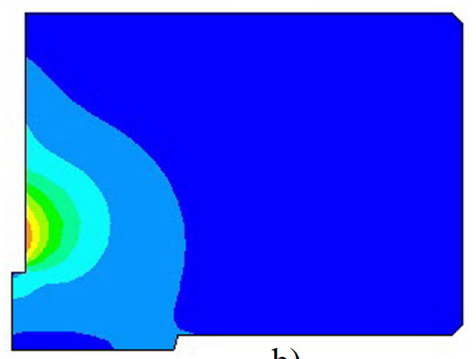

b)

Fig. 15. Radial displacement of the die in the case of nonhardened (a) and hardened (b) material $\left(e_{p}=2.11, \mathrm{~s}=18 \mathrm{~mm}\right.$ )

Table 2 shows the maximal elastic displacements of the inner die wall $\left(\Delta r_{\max }\right)$ for all five extrusion ratios and related in terms of international tolerance grade (IT) in order to display the influence of elastic deviation of the inner die wall on workpiece dimensional errors more transparently. Note that the maximal radial deviation of the inner die wall, i.e. the workpiece's outer surface, corresponds to IT8 to IT11 grades, which could be considered as a significant loss of accuracy. Therefore, in order to obtain proper dimensions of the final part, the elastic deformation of the die must be taken into account when designing the extrusion process. It should be noted that loss of tolerance of the workpiece is even greater than indicated in Table 2 due to the material elastic recovery after ejecting the workpiece from the die (Fig. 16).

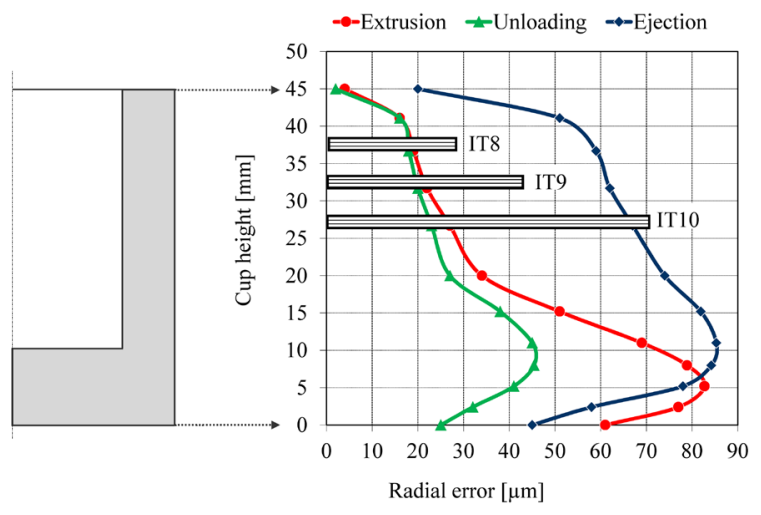

Fig. 16. FEM predicted radial errors of the extruded cup (punch stroke $\mathrm{s}=18 \mathrm{~mm} ; e_{p}=2.11$ )

\section{CONCLUSIONS}

Knowledge of die loading, especially contact pressure distribution along the die-workpiece interface, is one of the key factors for the correct design of a cold extrusion process. Loading influences both die life and the accuracy of the formed part.

In this paper, an efficient procedure to measure contact radial stresses on the inner die wall at various points in time and at various locations during the backward extrusion process is presented. For this purpose, a special device (a pin load cell inserted in the die with replaceable bottoms of various thicknesses) was designed. Experiments were performed using steel billets, with punches of different diameters.

Table 2. Maximal radial deviation of the die inner wall

\begin{tabular}{|c|c|c|c|c|c|c|}
\hline & & $\begin{array}{l}\Delta r_{\max }[\mathrm{mm}] \\
(\mathrm{s}=2 \mathrm{~mm})\end{array}$ & $\begin{array}{l}\Delta r_{\max }[\mathrm{mm}] \\
(\mathrm{s}=4 \mathrm{~mm})\end{array}$ & $\begin{array}{c}\Delta r_{\max }[\mathrm{mm}] \\
(\mathrm{s}=10 \mathrm{~mm})\end{array}$ & $\begin{array}{c}\Delta r_{\max }[\mathrm{mm}] \\
(s=14 \mathrm{~mm})\end{array}$ & $\begin{array}{c}\Delta r_{\max }[\mathrm{mm}] \\
(\mathrm{s}=18 \mathrm{~mm})\end{array}$ \\
\hline \multirow{2}{*}{$e_{p}=2.11$} & Exp. & 0.045 (IT10) & 0.080 (IT11) & 0.088 (IT11) & 0.102 (IT11) & 0.106 (IT11) \\
\hline & FEM & 0.048 (IT10) & 0.070 (IT10) & 0.086 (IT11) & 0.088 (IT11) & 0.083 (IT11) \\
\hline \multirow{2}{*}{$e_{p}=1.82$} & Exp. & 0.051 (IT10) & 0.067 (IT10) & 0.076 (IT11) & 0.084 (IT11) & 0.081 (IT11) \\
\hline & FEM & 0.042 (IT9) & 0.056 (IT10) & 0.068 (IT10) & 0.069 (IT10) & 0.065 (IT10) \\
\hline \multirow{2}{*}{$e_{p}=1.57$} & Exp & 0.030 (IT9) & 0.045 (IT10) & 0.057 (IT10) & 0.073 (IT11) & 0.076 (IT11) \\
\hline & FEM & 0.032 (IT9) & 0.045 (IT10) & 0.057 (IT10) & 0.057 (IT10) & 0.054 (IT10) \\
\hline \multirow{2}{*}{$e_{p}=1.35$} & Exp. & 0.025 (IT9) & 0.037 (IT9) & 0.048 (IT10) & 0.052 (IT10) & 0.053 (IT10) \\
\hline & FEM & 0.025 (IT8) & 0.034 (IT9) & 0.044 (IT10) & 0.046 (IT10) & 0.042 (IT9) \\
\hline \multirow{2}{*}{$e_{p}=1.22$} & Exp. & 0.019 (IT8) & 0.027 (IT8) & 0.034 (IT9) & 0.039 (IT9) & 0.043 (IT9) \\
\hline & FEM & 0.017 (IT7) & 0.025 (IT8) & 0.030 (IT9) & 0.036 (IT9) & 0.035 (IT9) \\
\hline
\end{tabular}


The influence of the punch position on the value and location of the maximal radial stress has been investigated. Furthermore, the analyzed process was simulated using Simufact.forming software.

Experimental and FEM results indicate that the radial stress distribution on the die wall surface during the extrusion is non-uniform. The values of the radial stress depend on the punch position and increases with increases in the punch stroke, whereas the peak is always located at the point just below the instantaneous position of the punch head. The influence of the extrusion ratio on the stress intensity is also noticeable. When $e_{p}$ increases, the peak value increases too: there is a more than twofold difference in the maximal radial stresses for the minimal $\left(e_{p}=1.22\right)$ and maximal $\left(e_{p}=2.11\right)$ extrusion ratio. A comparison of the FEM and experimental findings shows that the FEM predictions are $15 \%$ to $20 \%$ higher. There is very good agreement in the form of the stress distribution.

Another aim of the paper was to verify whether Lame's theory can accurately determine the elastic deformation of the extrusion dies. The results for the radial displacement of the inner die wall obtained by FEM and analytically by substituting the experimental values for the radial stress in Lame's formula differ significantly. This can be explained by the failure of Lame's equation to take into account different parameters such as variable die geometry and material hardness effect. Hence, it can be concluded that this solution is best applied in cases where the die has a simple geometry (uniform inner section profile) and uniform distribution of radial stress along the die wall, while for dies having complex shapes a more accurate theoretical model or different techniques like FEM are needed. Loss of tolerance due to the die elastic deformation may reach IT11 grade.

\section{ACKNOWLEDGEMENTS}

The authors thank the CEEPUS program for helping with mobility within the framework of the network CIII-HR-0108.

\section{REFERENCES}

[1] Vilotić, D., Plančak, M., Kuzman, K., Milutinović, M., Movrin, D., Skakun, P., Luzanin, O. (2007). Application of net shape and near-net shape forming technologies in manufacture of roller bearing components and cardan shafts. Journal for Technology of Plasticity, vol. 32, no. 1-2, p. 87-104.
[2] Altan, T., Ngaile, G., Shen, G. (eds.) (2004). Cold and Hot Forging: Fundamentals and Applications. ASM International, Materials Park.

[3] Groenbaek, J., Hinsel, Ch. (2001) The importance of optimized pre-stressing with regard to the tool performance in precision forging. 3rd International Conference on Industrial Tools, Celje, p. 41-48.

[4] Hayakawa, K., Nakamura, T., Tanaka, S. (2004) Analysis of fatigue crack initiation and propagation in cold forging tools by local approach of fracture. Materials Transactions, vol. 45, no. 2, p. 461-468, D0l:10.2320/matertrans.45.461.

[5] Lee, Y.S., Lee, J.H., Choi, J.U., Ishikawa, T. (2002). Experimental and analytical evaluation for elastic deformation behaviors of cold forging tool. Journal of Materials Processing Technology, vol. 127, no. 1, p. 73-82, Dol:10.1016/S09240136(02)00268-6.

[6] Lee, Y.S. Lee, J.H., Kwon, Y.N., Ishikawa, T. (2004) Analysis of elastic characteristics at the die and workpiece to improve the dimensional accuracy for cold forged part. Journal of Materials Processing Technology, vol. 153-154, p. 10811088, D0I:10.1016/J.jmatprotec.2004.04.291.

[7] Lange, K., Cser, L., Geiger, M., Kals, J.A.G. (1992). Tool life and tool quality in bulk metal forming. CIRP Annals - Manufacturing Technology, vol. 41, no. 2,, p. 667-675, D0l:10.1016/S00078506(07)63253-3.

[8] Milutinović, M., Movrin, D., Pepelnjak, T. (2012) Theoretical and experimental investigation of cold hobbing processes in cases of cone-like punch manufacturing. The International Journal of Advanced Manufacturing Technology, vol. 58, no. 9 , p. 895-906, DOI:10.1007/s00170-011-3457-5.

[9] Randjelović, S., Manić, M., Trajanović, M., Milutinović, M., Movrin, D. (2012). The impact of die angle on tool loading in the process of cold extruding steel. Materials and Technology, vol. 46, no. 2, p. 149-154.

[10] Lange, K. (ed.) (1985) Handbook of Metal Forming, McGrawHill Inc., New York

[11] Behrens, B.-A., Bouguecha, A., Raedt, H.W., Hadifi, T. (2010). Numerical investigations on the fatigue failure of forging tools due to thermo-mechanical cyclic loading. International Journal of Material Forming, vol. 3, suppl. 1, p. 339-342, D0l:10.1007/ s12289-010-0776-2.

[12] Brnic, J., Turkalj, G., Lanc, D., Canadija, M., Brcic, M., Vukelic, G., Munjas, N. (2013). Testing and analysis of X39CrMo17-1 steel properties. Construction and Building Materials, vol. 44, p. 293-301, DOI:10.1016/J.conbuildmat.2013.02.080.

[13] Geiger, M., Falk, B. (2001) Prediction of service life and failure probability of cold forging tools. CIRP Annals - Manufacturing Technology, vol. 50, no. 1, p. 173-176, D0l:10.1016/S00078506(07)62098-8.

[14] Long, H. (2006) Quantitative evaluation of dimensional errors of formed components in cold backward cup extrusion. Journal of Materials Processing Technology, vol. 177, no. 1-3, p. 591595, D0l:10.1016/j.jmatprotec.2006.04.079.

[15] Kwan, C.T., Wang, C.C. (2011). An optimal pre-stress die design of cold backward extrusion by RSM Method. Structural Longevity, vol. 15, no. 1, p. 25-32.

[16] Vazquez, V., Altan, T. (2000). New concepts in die design - physical and computer modeling applications. Journal of 
Materials Processing Technology, vol. 98, no. 2, p. 212-223, DOI:10.1016/S0924-0136(99)00202-2.

[17] Bingöl, S., Ayer, O., Altinbalik, T. (2015). Extrusion load prediction of gear-like profile for different die geometries using ANN and FEM with experimental verification. The International Journal of Advanced Manufacturing Technology, vol. 76, no. 5, p. 983-992, Dol:10.1007/s00170-014-6328-z.

[18] Milutinović, M. (2013). Investigation of Part Accuracy in Cold Bulk Metal Forming Processes, PhD thesis. University of Novi Sad, Faculty of Technical Sciences, Novi Sad.

[19] Vilotić, D., Plančak, M. (2011) Experimental tooling for contact stress measurement in bulk metal forming processes. Journal for Technology of Plasticity, vol. 36, no. 1, p. 9-16, DOI:10.2478/v10211-011-0004-1.
[20] EN-10027-2 (1992). Designation Systems for Steels - Part 2: Steel Numbers. European Committee for Standardisation, Brussels.

[21] Labergere, C., Rassineux, A., Saanouni, K. (2008) Improving numerical simulation of metal forming processes using adaptive remeshing technique. International Journal of Material Forming, vol. 1, suppl. 1, p.539-542, Dol:10.1007/ s12289-008-0255-1.

[22] Milutinović, M., Vilotić, D., Pepelnjak, T. (2014). Part dimensional errors in free upsetting due to the elastic springback. Tehnički vjesnik - Technical Gazette, vol. 21, no. 1, p. 135-140. 